\title{
2nd Joint Spring Meeting ACPGBI-SICCR, San Vito al Tagliamento, Italy, April 19th, 2013
}

\author{
A. Infantino $\cdot$ A. Lauretta
}

Received: 24 May 2013/ Accepted: 31 May 2013/Published online: 3 July 2013

(C) Springer-Verlag Italia 2013

The 2nd Joint Meeting of the Italian Society of Colorectal Surgery (SICCR) and the NE Thames chapter of the Association of Coloproctology of Great Britain and Ireland (ACPGBI) was held on the April 19, in San Vito al Tagliamento, in the Friuli Venezia Giulia region oft northeastern Italy. The first Conference had taken place at the prestigious University College Hospital in London, while the second took place in the splendid setting of the G Arrigoni theater built in the eighteenth century. Colorectal surgeons belonging to both societies discussed the hottest and most debated topics in the field, regarding both malignant and benign disease, with special consideration for all scientific-technological innovations that have been introduced in recent years. High-profile surgeons such as John Nicholls, Mike Parker, and Sue Clark, just to mention a few, have ensured that the scientific level was high. Miss Sue Clark, who has recently been appointed professor at Saint Mark's Hospital, started her lecture revealing that she felt like a singer on a stage in such a beautiful venue.
Extremely interesting talks were given throughout the entire congress leading to in-depth discussions and quite a few questions from the audience. Adela Brigic, a research fellow from Saint Mark's Hospital, won the prize for best podium presentation with her lecture "eFLEX: a new approach to local colonic full thickness resection," while Paolo Giamundo from Cuneo was the winner of the best video award with "Fi.La.C. (Laser Fistula Closure) in the treatment of fistula-in-ano: clinical results of a pilot study in one institution." The expectations of the meeting were met, as there was an equal exchange of experience and scientific information between members of the old and prestigious Anglo-Saxon association and members of the younger Italian society. As a result of the impressive organizing effort made by the scientific secretariat and Chairmen of the Conference, Prof. Aldo Infantino and Mr. Pasquale Giordano of the delegates left San Vito al Tagliamento looking forward to the 3rd Joint Spring Meeting which will be held in London on April 25, 2014.

A. Infantino $(\square) \cdot$ A. Lauretta

Departement of Surgery, Santa Maria dei Battuti Hospital, Via Savorgnano 2, 33079 San Vito al Tagliamento, PN, Italy e-mail: ainfantino@libero.it 